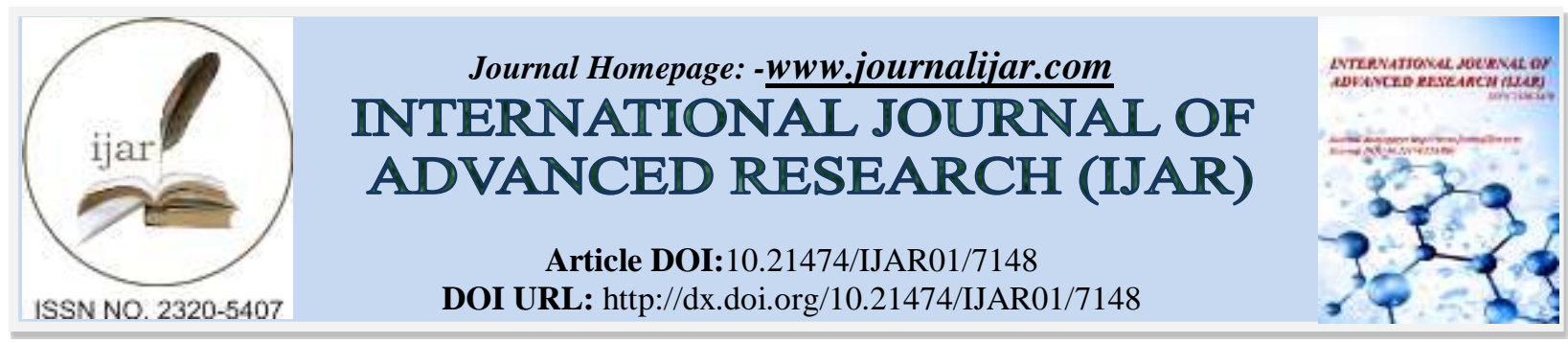

RESEARCH ARTICLE

\title{
ANALYSIS OF DETERMINANTS OF ACADEMIC INTEGRITY VIOLATIONS USING STATISTICAL PACKAGE FOR SOCIAL SCIENCES AND ANALYSIS OF MOMENT STRUCTURE.
}

Beenu Mago and Ahmed Al Gindy.

School of Engineering and Technology Al Dar University College Dubai, U.A.E.

\section{Manuscript Info}

Manuscript History

Received: 20 March 2018

Final Accepted: 22 April 2018

Published: May 2018

Keywords:-

SPSS, AMOS Cheating, Academic Integrity, Academic Cheating, Academic dishonesty.

\begin{abstract}
Violation of Academic integrity has become one of the major problems in education today. Academic Integrity is an ethical practice that means students are achieving academic success fairly. It suggests that all grades that are achieved are earned honestly. Cheating is one of the most common ways to disobey academic integrity. Statistics exist on various facets of cheating in high schools, colleges and universities and thus violating the academic integrity. The current study is conducted in United Arab Emirates - UAE to check the prevalence of academic integrity (cheating) among the students pursuing undergraduate and postgraduate courses in various universities in UAE. Questionnaire is used to collect the data for the current research. It is divided into three sections. Section A is used to get the demographic information of students. Section B is used to check the attitude of university students towards cheating. Section C consists of questions to find out the factor which influences the student to do cheating in exam. The survey instrument is distributed to 300 students with the approximate returns of $80 \%$. The data is analyzed using SPSS 20 and AMOS 21 to analyze the factors and other results of the study. The results shows that high job position, higher grades, less time to study, cheated in past, difficult course material, cheating environment are factors that encourage students to do cheating. This research is step towards finding the factors that force or motivates the students to do cheating. The current study further helps the management of universities and colleges to formulate the policies. It also gives insights to faculties to formulate strategies that will demotivate the students against cheating. The current research is an attempt to provide insights that can be used to develop a set of academic and administrative strategies to manage academic integrity effectively and efficiently.
\end{abstract}

Copy Right, IJAR, 2018,. All rights reserved.

\section{Introduction:-}

Violation of Academic integrity has become one of the major problems in education today. Academic Integrity is an ethical practice that means students are achieving academic success fairly. It suggests that all grades that are achieved are earned honestly. Cheating is one of the most common ways to disobey academic integrity. In the college setting, this equates to intentionally trying to deceive the instructor with regards to work completed by the 
student. The cheating behavior affects the integrity of the learning process, an individual's long-term behavior, and the ability of academic institutions to attain their stated missions. The current study aims to address the following questions.

1. Do the students in UAE universities know the meaning of cheating?

2. What motivates students to do cheating?

3. Does the gender plays a role in determining the cheating behavior of students in universities of UAE?

The results of this study will assist in providing insights into the reason behind the adoption of cheating behavior and the results are significant for the researchers, academicians, faculties and for the policy makers of universities.

\section{Literature Review:-}

For most educational institutions, academic Integrity is a key worth upon which the school, college or university institution relies upon for its students, faculty and administrators to bolster, keep up and maintain. The researches show that academic dishonesty is both a pervasive and developing issue in schools and colleges around the globe [1]. Literature shows that the researchers study the reasons behind the cheating behavior of students. They divide these factors in psychological [2-5], demographic [6], and situational [7]. Researchers also found that there is a strong correlation between student values and their cheating behavior [5]. Another researcher found that $64 \%$ of students who were involved in cheating in secondary school additionally swindled in university also [8]. There is a strong relationship between cheating in high school and cheating in college [9-11]. Research also shows gender of student doesn't have any impact on the cheating behavior of the student [12]. In the Arabic literature, research done on undergraduate student, also studies the same phenomenon [13, 14, and 15]. The literature shows that $54 \%$ male students and $47 \%$ female students are involved in cheating [16].

In the literature many types of academic dishonesty have been observed. For instance, the joint effort while doing assignments, totally or incompletely replicating a task from another student, utilizing the Internet as a hotspot for help for tackling troublesome issues, presenting the same work for different courses, replicating content from another source (book,

Web, and so on.), paying somebody to do a task, utilizing hidden sources a mid an exam, and numerous different structures [17].

Meade responded a dishonesty rate of 87 percent among undergraduates' at 31 top universities in the United States [18]. On the other hand, Diekhoff et al found that Japanese students were involved in various acts of academic dishonesty at a rate of 55 percent [19]. Similarly, Lupton and Chapman reported a dishonesty rate of 84 percent in Poland and 64 percent in Russia [20]. These results show that cheating is there in whole world and this issue needs to be addressed academically. The literature also shows that very little research related to cheating behavior of students is done in UAE. This motivates the researchers to conduct the above mentioned research in UAE.

It is further evident from the literature that students have extensive variety of reasons for involving in cheating and they justified the reasons to be involved in cheating by providing variety of reasons [21, 22]. Mc cabe in his studies found that pressure to get higher grades, a desire to excel, lack of preparation and pressure to gain employment upon completion of study are the reasons that inspires students to do cheating [23]. Academic dishonesty could be justified in certain situations including: when there are parental pressures to do well; to remain academically competitive with others students; and excessive work load or assessment standards set by lecturers and tutors [23]. Various studies demonstrate that students might probably cheat when they see cheating as not unethical or not a genuine type of offense. [24]. Thus, peer association in cheating activities is another relevant element that can prompt student's infringement of scholarly trustworthiness rules [25]. All these studies give the clear indication that students are involved in cheating and the issue needs to be addressed.

Although there are many researches done in different part of world but very little research have been done in UAE. This generates a need to study the factors that motivates the students of UAE universities to cheat. Based on above literature review, the authors have proposed the following model. As per the proposed model, the factors that motivate the student to do cheating are: getting higher positions in job, getting higher grades, less time to study, cheating in past, difficult course material and cheating environment. 


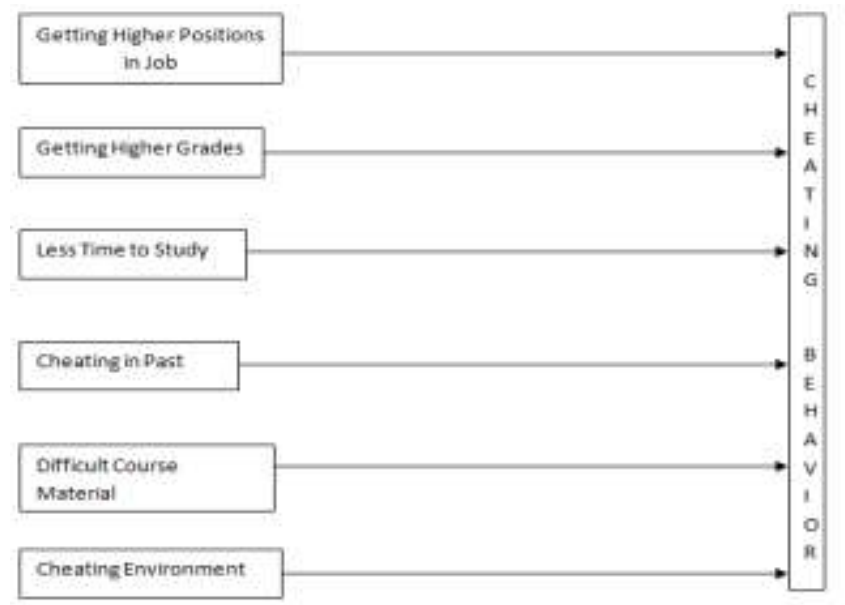

Figure 1:-Proposed Model

Based on above proposed model, following hypothesis is formulated.

H1:-Getting higher position in job is positively related to cheating behavior of students in UAE.

H2:-Getting higher grades is positively related to cheating behavior of students in UAE.

H3:-Getting less time to study is positively related to cheating behavior of students in UAE.

H4:-Cheating in past is positively related to cheating behavior of students in UAE.

H5:-Difficult course material is positively related to cheating behavior of students in UAE.

H6:-Cheating environment is positively related to cheating behavior of students in UAE.

\section{Research Methods:-}

The structured scale was taken after extensive literature review. The questionnaire is divided into three sections. Section A is used to get the demographic information of students. Section B is used to check the attitude of university students towards cheating. Section $\mathrm{C}$ consists of questions to find out factors which motivate the students to do cheating. The questions were structured using 5-point Likert scale which ranges from strongly agree 5 , agree $=$ 4 , neutral $=3$, disagree $=2$ and strongly disagree $=1$. The students were assessed using items taken from research done by Carpenter, Harding, Finelli, Susan, Honor [26]. Questionnaire was distributed to 300 respondents which were selected by convenience method of sampling in UAE. Out of these 300 questionnaires, 240 are considered as complete and retained for further data analysis. Others were discarded on account of incomplete information. The reliability of questionnaire is tested using Cronbach alpha test using SPSS 20 which was .865 which is highly acceptable as a rule of thumb [27].

\section{Analysis:-}

The data collected shows that there are $144(60 \%)$ male and $96(40 \%)$ female respondents out of 240 respondents. $108(45 \%)$ respondents are enrolled for graduate program and $132(55 \%)$ respondents are doing post-graduate program. Further, the demographics of data also shows that $144(60 \%)$ of the respondents are working as full time employee, $60(25 \%)$ respondents are working as part time employees and $36(15 \%)$ of the respondents are nonworking. The respondents belong to different age group also. There are questions that were asked to know the awareness of cheating among the students in UAE. The results show that students don't have clear understanding of what is cheating and what is not. $30 \%$ of students agree that telling or asking something to friend during the assessment is cheating and $70 \%$ students consider it as a help.

Researchers used AMOS 20 to check the relationship between various variables. In this research, First measurement model is developed which is part of confirmatory factor analysis and then Structural equation modeling or path analysis is used to check the hypothesized relationship. Measurement model is used to check the relationship between observed variables and constructs.

\section{Measurement Model:-}

Measurement model defines the relationship between measured or observed variables and constructs or factors. In this model, all constructs are interdependent and treated as exogenous variables. After getting several models, 
researcher considered the following measurement model. The goodness-of-fit indices for this model are given below.

Table 1:-Fit indices for Measurement Model

\begin{tabular}{|c|c|c|c|c|c|}
\hline Model & Chi-Square & Df & Normed Chi-Square & RMSEA & CF \\
\hline Measurement Model & 263.920 & 142 & 1.828 & .062 & .921 \\
\hline
\end{tabular}

The models have normed chi square of less than 3. RMSEA values are also less then maximum of 0.08 and CFI is greater than minimum required value of 0.90 . In the current study, the researchers have used CFI as incremental fit index and chi-square, normed chi-square, Root Mean Square Error Approximation as used to test absolute fit index of data. This model is achieved by removing unacceptable items with low factor loadings usually less than equal to 0.5 , preferably with factor loadings value is 0.70 and above.

Table 2 shows that the values of correlation coefficient between the various factors. The values shows there exists relationship between the variables and cheating behavior. That means there exists correlation between getting higher positions in job, getting higher grades, less time to study, cheating in past, difficult course material and cheating environment and cheating behavior.

Table 2:-Correlation

\begin{tabular}{|l|c|c|c|}
\hline \multicolumn{2}{|l|}{} & Estimate \\
\hline Getting Higher Positions & $\langle-\rangle$ & Cheating Behavior & .747 \\
\hline Getting Higher Grades & $\langle-\rangle$ & Cheating Behavior & .709 \\
\hline Less Time to Study & $\langle-\rangle$ & Cheating Behavior & .674 \\
\hline Cheating in Past & $<->$ & Cheating Behavior & .635 \\
\hline Difficult Course Material & $\langle-\rangle$ & Cheating Behavior & .575 \\
\hline Cheating Environment & $<->$ & Cheating Behavior & .546 \\
\hline
\end{tabular}

\section{Structural Model:-}

Again the absolute fit and incremental fit indices are used for goodness-of-fit test and path coefficient for analyzing the reliability of paths hypothesized. The goodness-of-fit indices that are absolute and incremental indices for the structured model are given below.

Table 3:-Fit indices for Structured Model

\begin{tabular}{|c|c|c|c|c|c|}
\hline Model & Chi-Square & Df & Normed Chi-Square & RMSEA & CFI \\
\hline Structured Model & 264.930 & 140 & 1.726 & .060 & .943 \\
\hline
\end{tabular}

The above table shows that the structured model has absolute indices (Normed chi-square and RMSEA) are less than 0.3 and increment indices is greater than 0.9 which confirms the goodness-of-fit of the model. The statistics are same as those of the best fit measurement model used for structural model.

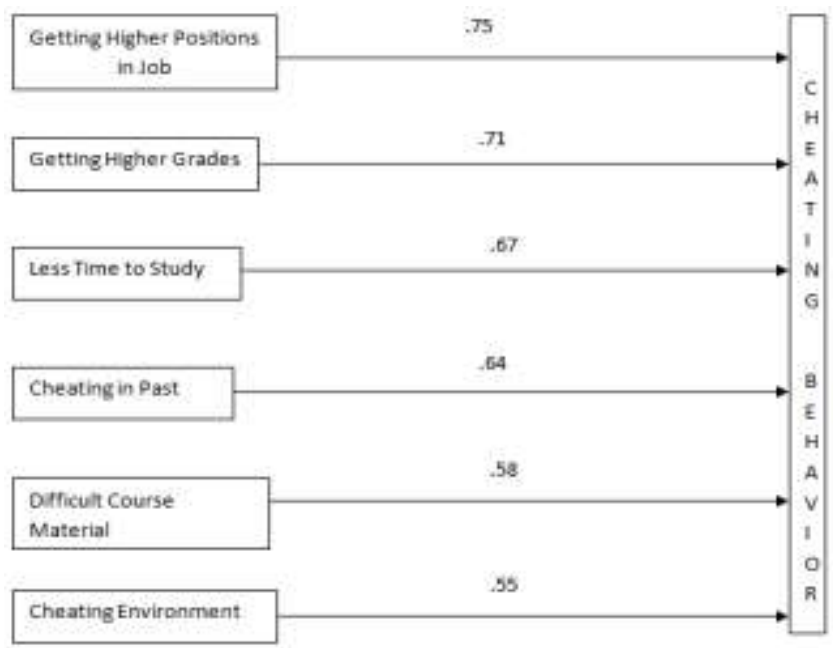

Figure 2:-Structural Model 
The test of the structural model includes estimating the path coefficients, which indicate the strengths of the relationships between the independent and dependent variables. The overall results of the analysis are shown in Figure 2. The significance level is $95 \%$. Path coefficients are used to test the hypothesized relationships between dependent and independent variables. Accordingly, following hypothesis are accepted

H1. Getting higher position (path coefficient $=.75$ ) in job is positively related to cheating behavior of students in UAE.

H2. Getting higher grades (path coefficient $=.71$ ) is positively related to cheating behavior of students in UAE.

H3. Getting less time to study (path coefficient $=.67$ ) is positively related to cheating behavior of students in UAE. H4. Cheating in past (path coefficient $=.64$ ) is positively related to cheating behavior of students in UAE.

H5. Difficult course material (path coefficient =.58) is positively related to cheating behavior of students in UAE. H6 Cheating environment (path coefficient $=.55$ ) is positively related to cheating behavior of students in UAE.

To know the effect of gender on cheating behavior, the overall average score was taken for male and female responses. The difference in average responses of male and females is very small which shows that cheating behavior is almost same irrespective of gender. The results are further checked and confirmed by independent $\mathrm{t}$-test for male and female respondents. The result was statistically insignificant $(\mathrm{p}=.062, \mathrm{t}=1.99)$.

\section{Discussion and Conclusion:-}

The results of the study will contribute to the factors which motivates the students to do cheating in UAE. The results indicates that Getting higher positions in job is the one of the most important factor that contribute most to the cheating behavior of the students. Getting higher grades and less time to study are the next contributing factors. This result at the same time might be because of the fact that the majority of the respondents are working. This gives a great insight to the government and policy makers of universities. Grades should not be the sole criterion to get appraisal or to move to the higher position. Similarly, higher GPA should not be the criterion to get scholarship in academics. Along with it, person should be judged with the help of some competitive tests. These competitive tests will motivate the students to get knowledge rather than getting higher grades and to do cheating. Less time to study and difficult course material are other factors that contribute to cheating behavior of the students in UAE. The results are significant to the faculties, curriculum and course developer's, and student counselors. Faculties should follow teaching methodologies which are more effective towards learning. The assessment should be done in a way to assess knowledge of the student. The results also indicate that there is a strong need to generate awareness about cheating among the students in UAE. Students need to be oriented about the university cheating policy.

This study is not without limitations. The results of the study can't be generalized as the study is conducted only in UAE. Secondly, the findings need to be confirmed with large sample size. Thirdly, the future research is required to check the co-relationship between each factor of cheating behavior. 


\section{References:-}

1. McCabe DL, Feghali T, Abdallah H, "Academic dishonesty in the Middle East: individual and contextual factors.", Res High Educ 49:451-467, 2008

2. LaBeff, E.E., R.E. Clark, V.J. Haines, and G.M. Diekhoff, "Situational Ethics and College Student Cheating," Sociological Inquiry, Vol. 60, 1990, pp. 190-197.

3. Perry, A.R., K.M. Kane, K.J. Bernesser, and P.T. Spicker, “Type A Behavior, Competitive Achievement-striving, and Cheating Among College Students,” Psychological Reports, Vol. 66, 1990, pp. 459-465.

4. Ward, D.A., and W.L. Beck, "Gender and Dishonesty," Journal of Social Psychology, Vol. 130, 1990, pp. $333-339$.

5. Roth, N.L., and D.L. McCabe, "Communication Strategies for Addressing Academic Dishonesty," Journal of College Student Development, Vol. 36, No. 6, 1995, pp. 531-541

6. Stern, E.B., and L. Havlicek, "Academic Misconduct: Results of Faculty and Undergraduate Student Surveys," Journal of Allied Health, Vol. 15, No. 2, 1986, pp. 129-142

7. McCabe, D.L. and L.K. Trevino, “Academic Dishonesty: Honor Codes and Other Contextual Influences," Journal of Higher Education, Vol. 64, 1993, pp. 22-538.

8. Webster's New World Dictionary, 2nd Edition, Warner Books, New York, New York, 1984.

9. Harding, T.S., D.D. Carpenter, C.J. Finelli, and H.J. Passow, "The Relationship Between Academic Dishonesty and Unethical Behavior in Engineering Practice," Proceedings of the 2003 Ethics and Social Responsi-bility in Engineering and Technology Conference,November 15-17, 2003,New Orleans, Louisiana.

10. Harding, T.S., D.D. Carpenter, C.J. Finelli, and H.J. Passow, "The Influence of Academic Dishonesty on Ethical Decision Making in

11. the Workplace: A Study of Engineering Students," Proceedings of the 2004 ASEE Conference and Exposition, June 10-15, 2004, Salt Lake City, Utah.

12. Harding, T.S., D.D. Carpenter, C.J. Finelli, and H.J. Passow, "Does Academic Dishonesty Relate to Unethical Behavior in Professional Practice? An Exploratory Study," Journal of Ethics and Social Values, Vol. 10, No. 2, 2004, pp. 311-324

13. Whitley, Jr., B.E., A. Bichlmeier, and C.J. Jones, "Gender Differ-ences in Cheating Attitudes and Classroom Cheating Behavior: A Meta Analysis," Sex Roles, Vol. 41, No. 9, 1999, pp. 657-680

14. Abdelkaleq, R., \& Suliman, R., "Cheating in exams: Reasons and methods",. The 7th of April University, Zleteen, Libya, 1993

15. AbedRaboh, A. , "Cheating phenomenon among university students: Effects on academic level and educational system.”, Journal of Educational Studies, 63, Cairo, Egypt, 1994

16. Ibraheem, A., "Cheating in exams and its relationship with some psychological variables and learning styles", Journal of Educational Studies, 63, Cairo, Egypt,1994

17. Jaber, A., "Studies in educational psychology", Cairo: Book World, 1980

18. Sheard, J., Markham, S., \& Dick, M. Investigating differences in cheating behaviours of IT undergraduate and graduate students: The maturity and motivation factors. Higher Education Research and Development, 22(1),2003, 91-108.

19. Meade.J., "Cheating: Is academic dishonesty par for the course?", Prism 1 (7)30-32, 1992

20. Diekhoff, G. M., LaBeff. E. E., Shinohara, K., \& Clark, R. E.," College cheating in Japan and the United States",Research in Higher Education 40 (3):343-353.,1999

21. Lupton, R. A., and Chapman, K. J.," Russian and American college students' attitudes, perceptions and tendencies toward cheating.", Educational Research 44 ( 1):17-27, 2002

22. Brimble M, Stevenson-Clarke P,"Perceptions of the prevalence and seriousness of academic dishonesty in Australianuniversities.", Aust Educ Res 32:19-44,2005

23. De Lambert K, Ellen N, Taylor L,"Cheating-what is it and why do it: a study in New Zealand tertiary institutions of the perceptions and justifications for academic dishonesty.”, J Am Acad Bus Camb 3:98-103,2003

24. McCabe DL, Trevino LK, Butterfield KD, "Academic integrity in honor code and non-honor code environments: a qualitative investigation.", J

25. High Educ 70:211-234,1999

26. Bolin AU, "Self-control, perceived opportunity, and attitudes as predictors of academic dishonesty.", J Psychol 138:101-114,2004.

27. Brimble M, Stevenson-Clarke P, "Perceptions of the prevalence and seriousness of academic dishonesty in Australian universities.", Aust Educ Res 32:19-44, 2005

28. Carpenter, Donald D.; Harding, Trevor S.; Finelli, Cynthia J.; Montgomery,

29. Susan M.; Passow, Honor J., "Engineering Students' Perceptions of and Attitudes Towards Cheating." Journal of Engineering Education 95(3). http://hdl.handle.net/2027.42/94862, 2006

30. Saunders, M. N.K., Thornhill, A., Lewis, P., Research Methods for Business Students. Financial Times Prentice Hall, 2009 